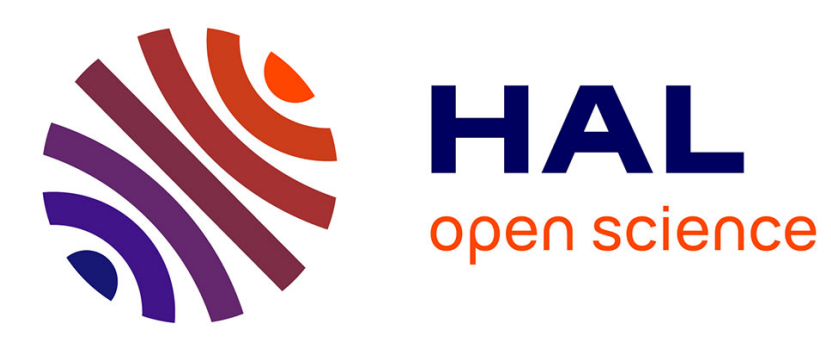

\title{
A PAPR upper bound of generalized waveforms for multi-carrier modulation systems
}

Marwa Chafii, Jacques Palicot, Rémi Gribonval

\section{To cite this version:}

Marwa Chafii, Jacques Palicot, Rémi Gribonval. A PAPR upper bound of generalized waveforms for multi-carrier modulation systems. 6th International Symposium on Communications, Control, and Signal Processing - ISCCSP 2014, May 2014, Athènes, Greece. pp.461 - 464, 10.1109/ISCCSP.2014.6877913 . hal-01072519

HAL Id: hal-01072519

https://hal-centralesupelec.archives-ouvertes.fr/hal-01072519

Submitted on 13 Mar 2015

HAL is a multi-disciplinary open access archive for the deposit and dissemination of scientific research documents, whether they are published or not. The documents may come from teaching and research institutions in France or abroad, or from public or private research centers.
L'archive ouverte pluridisciplinaire HAL, est destinée au dépôt et à la diffusion de documents scientifiques de niveau recherche, publiés ou non, émanant des établissements d'enseignement et de recherche français ou étrangers, des laboratoires publics ou privés. 


\section{A PAPR UPPER BOUND OF GENERALIZED WAVEFORMS FOR MULTI-CARRIER MODULATION SYSTEMS}

Marwa Chafii, Jacques Palicot

SUPELEC/IETR

\{marwa.chafii, jacques.palicot\} @ supelec.fr 35576 Cesson - Sévigné Cedex, France

\author{
Rémi Gribonval \\ Inria Rennes - Bretagne Atlantique \\ remi.gribonval@inria.fr \\ 35042 Rennes Cedex, France
}

\begin{abstract}
The most common way to study the Peak-to-average Power Ratio (PAPR) distribution is limited to a single Orthogonal Frequency Division Multiplexing (OFDM) symbol, therefore it does not reflect the exact value of the PAPR, since we have more than one OFDM symbol in practice. In this paper, we consider the Generalized Waveforms for Multi-Carrier (GWMC) modulation system which is based on any family of modulation functions, and we derive an upper bound of its PAPR. To the best of our knowledge, this is the first work that interprets the behaviour of the Complementary Cumulative Distribution Function (CCDF) of the PAPR for different number of GWMC symbols, and presents an asymptotic study for an infinite number of GWMC symbols.
\end{abstract}

Index Terms - PAPR, Generalized Waveforms for Multi-Carrier (GWMC), OFDM, upper bound.

\section{INTRODUCTION}

Orthogonal Frequency Division Multiplexing (OFDM) is a technique to send information over several orthogonal carriers in a parallel fashion. This system has been adopted in many standards thanks to its robustness against frequency selective channels and its optimal use of the bandwidth. However, the OFDM signal presents large amplitude variations compared to a single carrier signal, because it is the sum of many narrowband signals in the time domain with different amplitudes. Based on this fact, in-band and out-of-band distortions occur during the introduction of the signal into a non linear device, as the High Power Amplifier (HPA). To study these high amplitude fluctuations, the Peak-to-average Power Ratio (PAPR) has been defined. The PAPR is a random variable, as the symbols arrive randomly at the modulation input. There are two ways to study this measure, one is based on the static approach that expresses the maximum of the PAPR as equal to the number of carriers [1], the other one analyses the Complementary Cumulative Distribution Function (CCDF) of the PAPR [2], [3], [4]. In these studies, the PAPR has been defined over one OFDM symbol, and the derivation of its distribution is based on the observation of this single OFDM sym- bol. In our work in [5], a general distribution for the Generalized Waveforms for Multi-Carrier (GWMC) signal, based on the observation of several GWMC symbols, has been derived. In this paper, we first describe the GWMC system considered in our derivations in Section 2. In Section 3, we derive an upper bound of the PAPR for the GWMC signal. We show how the observation duration changes the PAPR behavior in Section 4.1. The infinite observation case is also presented and analyzed in Section 4.2. Finally, Section 5 concludes the paper.

\section{SYSTEM DESCRIPTION}

We assume a continuous infinite data transmitting over the time, using a digital modulation scheme. We decompose the sequence of symbols into several blocks of symbols, with same duration $T$. Every block is inserted in parallel in a GWMC modulation system. At the output of the modulator, the GWMC signal can be expressed as [5]:

$$
X(t)=\sum_{n \in \mathbb{Z}} \sum_{m=0}^{M-1} C_{m, n} \underbrace{g_{m}(t-n T)}_{g_{m, n}(t)}
$$

- $M$ : number of carriers that we assume greater than 8 to exploit the results of [5],

- $C_{m, n}$ : input symbols from a mapping technique, that take complex values and assumed with zero mean,

- $\left(g_{m}\right)_{m \in \llbracket 0, M-1 \rrbracket}: \in L^{2}(\mathbb{R})$ (the space of square integrable functions), family of functions representing the modulation system. 


\section{UPPER BOUND OF THE PAPR}

For an infinite transmission over time and any observation interval $I$, the PAPR of the GWMC signal can be defined as:

$$
\begin{aligned}
\operatorname{PAPR}_{c}(I) & =\frac{\max _{t \in I}|X(t)|^{2}}{P_{c, \text { mean }}} \\
\text { where } P_{c, \text { mean }} & =\lim _{t_{0} \rightarrow+\infty} \frac{1}{2 t_{0}} \int_{-t_{0}}^{t_{0}} E\left(|X(t)|^{2}\right) d t \\
& =\frac{\sigma_{C}^{2}}{T} \sum_{m=0}^{M-1}\left\|g_{m}\right\|^{2} .
\end{aligned}
$$

Note that $\left\|g_{m}\right\|^{2}=\int_{-\infty}^{+\infty}\left|g_{m}(t)\right|^{2} d t, \sigma_{C}^{2}=E\left(\left|C_{m, n}\right|^{2}\right)$ means the variance, and the subscript $c$ corresponds to the continuous-time context. For the details of the mean power derivation, the reader can refer to [6] for the BFDM ${ }^{1}$ case, and to our work [5] for the general case.

The aim here is to find an upper bound of the PAPR for a GWMC signal. Then, letting $M$ be a finite number of carriers, and $\left(g_{m}\right)_{m \in \llbracket 0, M-1 \rrbracket}$ be a family of modulation functions that satisfies $A_{i}^{i}=\min _{m, t} \sum_{n \in \mathbb{Z}}\left|g_{m}(t-n T)\right|^{i}>0$ and $B_{i}^{i}=\max _{m, t} \sum_{n \in \mathbb{Z}}\left|g_{m}(t-n T)\right|^{i}<+\infty$ for $i \in\{1,2\}$,

$$
\begin{aligned}
\text { we have } \max _{t \in I}|X(t)| & =\max _{t \in I}\left|\sum_{n \in \mathbb{Z}} \sum_{m=0}^{M-1} C_{m, n} g_{m}(t-n T)\right| \\
& \leq \max _{t \in I} \sum_{m=0}^{M-1}\left|\sum_{n \in \mathbb{Z}} C_{m, n} g_{m}(t-n T)\right| \\
& \leq \max _{m, n} \sum_{m=0}^{M-1}\left|C_{m, n}\right| \sum_{n \in \mathbb{Z}}\left|g_{m}(t-n T)\right| \\
& \leq M \max _{m, n}\left|C_{m, n}\right| B_{1}, \\
\text { and we have } P_{c, \text { mean }} & =\frac{\sigma_{C}^{2}}{T} \sum_{m=0}^{M-1} \int_{-\frac{T}{2}}^{\frac{T}{2}} \sum_{n \in \mathbb{Z}}\left|g_{m}(t-n T)\right|^{2} d t \\
\text { hence } M A_{2}^{2} \sigma_{C}^{2} & \leq P_{c, m e a n} \leq M B_{2}^{2} \sigma_{C}^{2}
\end{aligned}
$$

Thus, from Eq.(4) and Eq.(5), we have:

Property. (An upper bound of the PAPR for the GWMC system)

For any observation interval I and any input symbols,

$\operatorname{PAPR}_{c}(I) \leq \frac{\max _{m, n}\left|C_{m, n}\right|^{2} B_{1}^{2}}{\sigma_{C}^{2} A_{2}^{2}} M:=\operatorname{PAPR}_{c, \text { bound }}$

Note that: $\operatorname{PAPR}_{c, \text { sup }}=\sup _{I} \operatorname{PAPR}_{c}(I) \leq \operatorname{PAPR}_{c, \text { bound }}$

\subsection{Examples}

Hereafter, we give an upper bound of the PAPR for some particular modulation systems applying the Eq.(6).

\footnotetext{
${ }^{1}$ Biorthogonal Frequency Division Multiplexing
}

- For input symbols using the Quadrature Amplitude Modulation (QAM) scheme of $K$ states, we have: $\max _{m, n}\left|C_{m, n}\right|^{2}=2(\sqrt{K}-1)^{2}$ and $\sigma_{C}^{2}=\frac{2}{3}(\sqrt{K}-1)$,

$$
\text { then } \quad \operatorname{PAPR}_{c, \text { bound }}=M \frac{3 B_{1}^{2}(\sqrt{K}-1)}{A_{2}^{2} \sqrt{K}+1} .
$$

- For input symbols using the Phase-Shift Keying (PSK) modulation scheme, the value of the maximum power is equal to the mean power, the envelope is then constant,

$$
\text { thus } \quad \operatorname{PAPR}_{c, \text { bound }}=M \frac{B_{1}^{2}}{A_{2}^{2}} \text {. }
$$

- Let us consider now the OFDM system, we have:

$$
\begin{aligned}
\left|g_{m}(t-n T)\right| & =\left|\mathrm{e}^{\frac{j 2 \pi m(t-n T)}{T}} \Pi_{[0, T]}(t-n T)\right| \\
\text { where } \Pi_{[0, T]} & = \begin{cases}1 & \text { if } 0 \leq t \leq T \\
0 & \text { else }\end{cases} \\
\text { hence } A_{2}^{2}=B_{1}^{2} & =1, \\
\text { and } \text { PAPR }_{c, \text { bound }} & =\frac{\max _{m, n}\left|C_{m, n}\right|^{2}}{\sigma_{C}^{2}} M
\end{aligned}
$$

We can observe that Eq.(8) corresponds to the same expression obtained by S. Zabre in [7] and D. Guel in [8]. Thus, for the case of OFDM with PSK modulation scheme, combining Eq.(7) with Eq.(8), we get:

$$
\mathrm{PAPR}_{c, \text { bound }}=M \text {. }
$$

In this case the upper bound is reached, and then $\mathrm{PAPR}_{c, \text { bound }}=\mathrm{PAPR}_{c, \text { sup }}$.

- For the Nonorthogonal FDM (NOFDM) [9] system, considering Hamming window, we have:

$$
\begin{aligned}
& g_{m}(t)=\mathrm{e}^{\frac{j 2 \pi m t}{T} w(t),} \\
& w(t)=\left\{\begin{array}{l}
0.54-0.46 \cos \left(2 \pi \frac{t}{T}\right) \text { if } 0 \leq t \leq T \\
0 \quad \text { else }
\end{array}\right. \\
& \text { hence } A_{2}^{2}=(0.08)^{2} \text { and } B_{1}^{2}=1, \\
& \text { then } \operatorname{PAPR}_{c, \text { bound }}=\frac{\max _{m, n}\left|C_{m, n}\right|^{2}}{6.4 \times 10^{-3} \sigma_{C}^{2}} M .
\end{aligned}
$$

\section{CCDF OF THE PAPR OVER SEVERAL GWMC SYMBOLS}

The CCDF is usually used in the literature as a performance criterion of the PAPR. It describes the probability that a realvalued random variable with a given probability distribution will be found at a certain value greater than or equal to $\gamma$.

In Section 3, we have shown that the PAPR can not exceed the PAPR $\mathrm{PA}_{c \text { bound }}$ value, therefore, there is a finite $\mathrm{PAPR}_{c \text {,sup }}$ such that,

$$
\text { for any } I \text { and } \gamma>\operatorname{PAPR}_{c, \text { sup }} \operatorname{Pr}\left(\operatorname{PAPR}_{c}(I) \geq \gamma\right)=0 \text {. }
$$


Now, let $\gamma \leq \mathrm{PAPR}_{c \text {,sup }}$. We have two approaches for the PAPR analysis. The first involves the finite observation case in Section 4.1 and the second is the infinite observation case in Section 4.2. The analysis is performed in the discrete case, and the latest results are still applicable.

\subsection{Finite observation duration}

For a finite observation duration limited to $N$ GWMC symbols, and for $\gamma$ sufficiently small compared with PAPR , sup, the CCDF of the PAPR is expressed as follows [5]:

$$
\begin{aligned}
& \operatorname{Pr}\left(\operatorname{PAPR}_{d}^{N} \geq \gamma\right) \approx 1-\prod_{k \in \llbracket 0, N P-1 \rrbracket}\left[1-\mathrm{e}^{-x(k) \gamma}\right], \\
& \text { with } \quad x(k)=\frac{\sum_{m=0}^{M-1}\left\|g_{m}\right\|^{2}}{P \sum_{n \in \mathbb{Z}} \sum_{m=0}^{M-1}\left|g_{m}(k-n P)\right|^{2}} .
\end{aligned}
$$

$P$ is the number of samples existing in one GWMC symbol. The subscript $d$ corresponds to the discrete-time context, and the exponent $N$ is a finite number of GWMC symbols considered in our observation. In the case of the conventional OFDM, we have:

$$
\operatorname{Pr}\left(\operatorname{PAPR}_{d}^{N} \geq \gamma\right) \approx 1-\left[1-\mathrm{e}^{-\gamma}\right]^{N M}
$$

We should note that the CCDF is an increasing function respect to $N$. As the number of OFDM symbols observed increases, the probability to have large peaks gets larger. Figure 1 shows the simulated CCDF of the PAPR for different number of OFDM symbols $N \in\{1,2,3,4\}$. We generate for each sequence of $N$ OFDM symbols, 10000 realizations using a (Quadrature Phase-Shift Keying) QPSK modulation scheme, with $M=64$. From Eq.(13), we can also mention that the

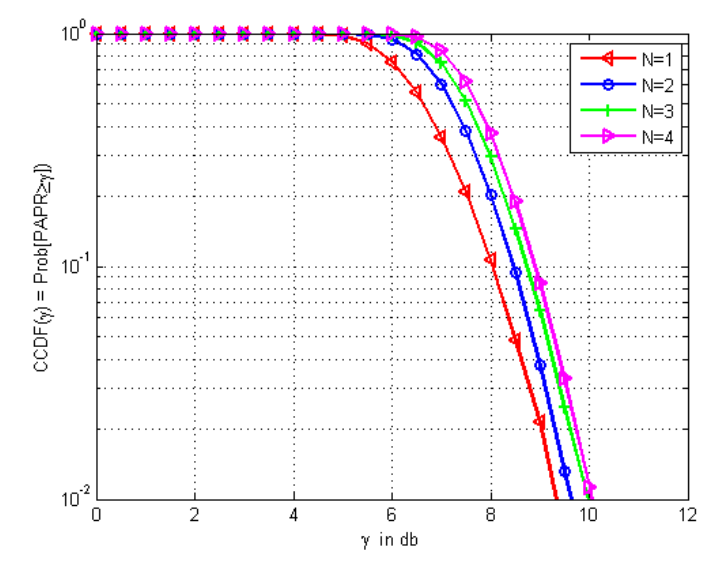

Fig. 1: Simulated CCDF of the PAPR for different number of GWMC symbols observed.

fact to increase the number $N$ of observed GWMC symbols by a multiplicative factor of $\alpha$ has the same effect of multiplying the number of carriers $M$ by the same factor $\alpha$. We can see this fact from the simulated CCDF in Figure 2, in which
Table 1: $\mathrm{N}$ and $\mathrm{M}$ relationship.

\begin{tabular}{|l|c|}
\cline { 2 - 2 } \multicolumn{1}{c|}{} & $\left(N_{1}, M_{1}\right) \Leftrightarrow\left(N_{2}, M_{2}\right)$ \\
\hline$N_{1} M_{1}=N_{2} M_{2}=N M=128$ & $(2,64) \Leftrightarrow(1,128)$ \\
$N_{1} M_{1}=N_{2} M_{2}=N M=256$ & $(4,64) \Leftrightarrow(1,256)$ \\
$N_{1} M_{1}=N_{2} M_{2}=N M=512$ & $(8,64) \Leftrightarrow(1,512)$ \\
\hline
\end{tabular}

we consider three values of $N M$ as defined in Table 1.

However, when $N$ goes to infinity, the shape of the CCDF

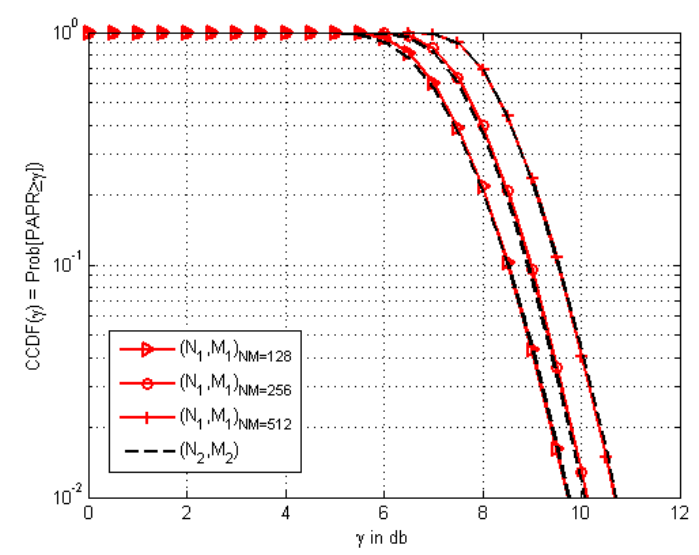

Fig. 2: Simulated CCDF of the PAPR showing the equivalence between increasing the observation duration $\mathrm{N}$ and the number of carriers $M$.

curve is not the same as when $M$ goes to infinity. In the following section we study this last case.

\subsection{Infinite observation duration}

for the infinite observation duration case, we have shown that the CCDF of the PAPR is expressed as [5]:

$$
\begin{aligned}
\operatorname{Pr}\left(\mathrm{PAPR}_{d}^{\infty} \geq \gamma\right) & \approx 1-\prod_{k \in \mathbb{N}}\left[1-\mathrm{e}^{-x(k) \gamma}\right], \\
\text { and } x(k) & =\frac{\sum_{m=0}^{M-1}\left\|g_{m}\right\|^{2}}{P \sum_{n \in \mathbb{Z}} \sum_{m=0}^{M-1}\left|g_{m}(k-n P)\right|^{2}} .
\end{aligned}
$$

From this expression, we notice that the probability that the PAPR exceeds a certain value $\gamma$ that is less or equal than PAPR $_{c, \text { sup }}$, is 1 , in fact:

$$
\begin{aligned}
& \text { we have } \sum_{m=0}^{M-1}\left\|g_{m}\right\|^{2}=\sum_{m=0}^{M-1} \sum_{n \in \mathbb{Z}} \sum_{k=0}^{P-1}\left|g_{m}(k-n P)\right|^{2} \\
& \text { then } A_{2}^{2} M P<\sum_{m=0}^{M-1}\left\|g_{m}\right\|^{2}<B_{2}^{2} M P \\
& \text { and } \frac{1}{B_{2}^{2} M P}<\frac{1}{P \sum_{n \in \mathbb{Z}} \sum_{m=0}^{M-1}\left|g_{m, n}(k)\right|^{2}}<\frac{1}{A_{2}^{2} M P}
\end{aligned}
$$




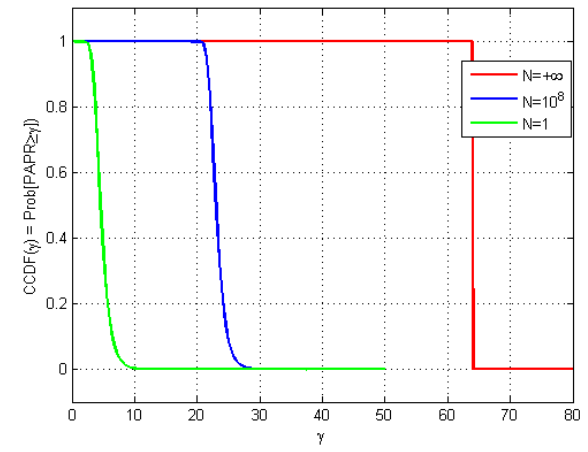

Fig. 3: CCDF of the PAPR for infinite observation duration.

From Eq.(15) and Eq.(16) we get:

$$
\begin{aligned}
\frac{A_{2}^{2}}{B_{2}^{2}} & <x(k)<\frac{B_{2}^{2}}{A_{2}^{2}}, \\
\text { hence } \quad 1-\mathrm{e}^{-x(k) \gamma} & <1-\mathrm{e}^{-\frac{B_{2}^{2}}{A_{2}^{2}} \gamma}<1 .
\end{aligned}
$$

Thus, for an infinite observation duration $(N \rightarrow+\infty)$, and for $\gamma$ sufficiently small compared with $\mathrm{PAPR}_{c \text {,sup }}$, we have

$$
\operatorname{Pr}\left(P A P R_{d}^{\infty} \geq \gamma\right)=1
$$

Considering OFDM system with PSK modulation scheme, Figure 3 represents the theoretical shape of the CCDF curve for an infinite observation duration, and Figure 4 shows the theoretical CCDF curve for an infinite number of carriers. We observe that for higher values of $N$, the CCDF is always upper bounded by the case $N=+\infty$, and for $M=+\infty$ we have a large peak for any value of $\gamma$.

We can conclude that, for an infinite observation duration, the equivalence between the number of GWMC symbols observed and the number of carriers, is not valid anymore.

\section{CONCLUSION}

In this paper, we have derived an upper bound of the PAPR for the GWMC signal for different digital modulation schemes. The PAPR distribution has been discussed for both finite and infinite observation duration. For the first case, we have proved that when we increase the number of OFDM symbols observed we increase the probability to have large peaks, we have also shown that the fact to increase the number of OFDM symbols observed has the same effect as to increase the number of carriers. For the second case, we developed an asymptotic study of the PAPR distribution function for an infinite observation duration and for an infinite number of carriers.

\section{ACKNOWLEDGEMENTS}

This work has received a French state support granted to the CominLabs excellence laboratory and managed by the National Research

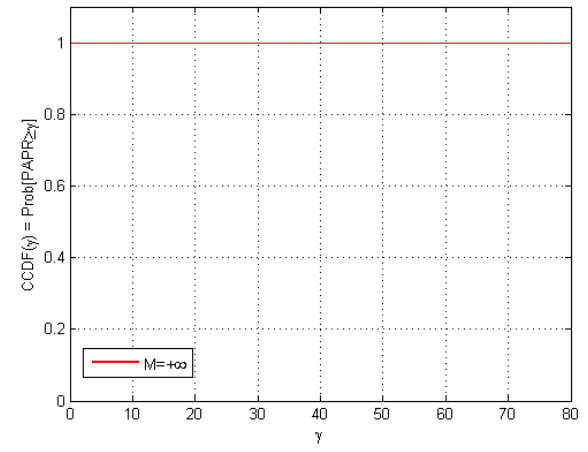

Fig. 4: CCDF of the PAPR for infinite number of carriers.

Agency in the "Investing for the Future" program under reference Nb. ANR-10-LABX-07-01. The authors would also like to thank the Region Bretagne, France, for its support of this work.

\section{REFERENCES}

[1] S. B. Slimane, "Peak-to-average power ratio reduction of OFDM signals using pulse shaping," in Global Telecommunications Conference, 2000. GLOBECOM'OO. IEEE. IEEE, 2000, vol. 3, pp. 1412-1416.

[2] R. V. Nee and R. Prasad, OFDM for wireless multimedia communications, Artech House, Inc., 2000.

[3] H. Ochiai and H. Imai, "On the distribution of the peak-toaverage power ratio in OFDM signals," Communications, IEEE Transactions on, vol. 49, no. 2, pp. 282-289, 2001.

[4] X. Zhou and J. Caffery Jr, "A new distribution bound and reduction scheme for OFDM PAPR," in Wireless Personal Multimedia Communications, 2002. The 5th International Symposium on. IEEE, 2002, vol. 1, pp. 158-162.

[5] M. Chafii, J. Palicot, and R. Gribonval, "Closed-form Approximations of the PAPR distribution for Multi-Carrier Modulation systems," submitted to Eusipco, Lisbon, Portugal, 2014.

[6] C. Siclet, Application de la théorie des bancs de filtres à l'analyse et à la conception de modulations multiporteuses orthogonales et biorthogonales, Ph.D. thesis, Rennes I University, France, 2002.

[7] S. Zabre, "Amplification non-linéaire d'un multiplex de porteuses modulées à fort facteur de crête," $P h D$. dissertation, Rennes I University, France, 2007.

[8] D. Guel, Étude de nouvelles techniques de réduction du «facteur de crête» à compatibilité descendante pour les systèmes multiporteuse, Ph.D. thesis, Rennes I University, France, 2009.

[9] Werner Kozek and Andreas F Molisch, "Nonorthogonal pulseshapes for multicarrier communications in doubly dispersive channels," Selected Areas in Communications, IEEE Journal on, vol. 16, no. 8, pp. 1579-1589, 1998. 